\title{
EFFECT OF HIGH - PRESSURE HYDROGEN ON FATIGUE PROPERTIES OF 34CrMo4 STEEL
}

\author{
Petr ČÍŽEK, Ladislav KANDER, Zdeněk KUBOŇ \\ MATERIAL AND METALLURGICAL RESEARCH Ltd., Ostrava, Czech Republic, EU, \\ petr.cizek@mmvyzkum.cz
}

https://doi.org/10.37904/metal.2019.849

\begin{abstract}
The paper deals with the effect of high-pressure hydrogen on fatigue crack growth rate of low alloy $34 \mathrm{CrMo} 4$ steel used for hydrogen cylinders production. Testing was performed on pre-cracked 1/2 C(T) specimens, which were dynamically loaded both in the air and in pure hydrogen environment at pressure $15 \mathrm{MPa}$. Fatigue crack growth was measured using potential method measuring system. Hydrogen effect was assessed from different curves fatigue crack growth rate in both environments. Fracture surface analysis subsequently confirmed significant effect of hydrogen on fatigue properties of this material.
\end{abstract}

Keywords: Fatigue crack growth rate, potential method, hydrogen autoclave applications

\section{INTRODUCTION}

Low alloyed steel $34 \mathrm{CrMo} 4$ belongs to typical representatives of materials used for production of hydrogen cylinders. To ensure of safe operation of cylinder in high pressure hydrogen environments is necessary to meet wide range of requirements given by standard [1] including chemical analysis, mechanical properties determined by tensile test, Charpy impact test, bend test, flattening test, metallography analysis of the bottom and also non-destructive ultrasonic testing. Besides these basic test methods is useful a knowledge of fatigue and fracture behavior in pure hydrogen environment at high pressure. European standard or specifications for cylinders prescribes several methods of testing which come out of static or dynamic loading of test specimens in hydrogen environment [2]. Main goal of this paper is to evaluate an effect of high-pressure hydrogen on fatigue crack growth rate of observed steel.

\section{APPARATUS AND TEST METHOD}

Pre-cracked 1/2C $(T)$ specimens produced from commercial cylinder in C-L orientation were used for testing. Choice of test specimen shape and dimensions came out from standard ISO 11114-4 [2] and also from diameter and wall thickness of original cylinder. In the last year MATERIAL AND METALLURGICAL RESEARCH Ltd. designed and produced an autoclave for material testing in high pressure hydrogen environment with volume 0,5 I which is protected by the patent No. 307390 of Czech Industrial Property Office. It can be used either for specimen exposure or for dynamic test in hydrogen or other different gaseous environments. In the second case is the autoclave built in servohydraulic testing machine MTS $100 \mathrm{kN}$. After clamping the specimen to the grips is autoclave closed and via system of piping and valves filled with pure hydrogen and pressurized to required pressure. In the laboratory are installed sensors for measurement of hydrogen leakage which secure safe work. General view of testing chamber is shown in Figure 1(a).

Because closed space of autoclave does not allow optical measurement of fatigue crack length, is necessary to use potential method for monitoring of the crack propagation during the experiment. Several potential methods were described for crack propagation monitoring and measurement. Basic principle of all methods is an introduction of electric current to the specimen and measurement of electric field. Main advantages of ACPD methods which use alternating current are lower electric current, smaller measuring apparatus, linear dependence of crack length on measuring signal or higher sensitivity to surface defects. Among the disadvantages belong difficult measurement of ferromagnetic materials and risk of affecting the results by 
power cables. On the other hand DCPD methods, which use direct current, allow exact measurement of ferromagnetic materials. Problems of these methods relate to higher current and consequently heating the specimens, non-linear calibration and errors caused by thermoelectric voltage. For the case of fatigue crack growth rate measurement is suitable to use test method developed by Korec [3]. This method combines advantages of ACPD and DCPD methods and is very well applicable to dynamically loaded specimens of C(T) type [4]. For this purpose is on the specimen surface welded a set of 2 or 3 pairs of electrodes intended to the power supply and measuring of electric potential. Detail of $1 / 2 \mathrm{C}(\mathrm{T})$ test specimen prepared for testing in hydrogen autoclave with welded electrodes for potential method is shown in Figure 1(b). Resultant crack length is subsequently derived from calibration curves created for this shape and proportional specimen dimensions.

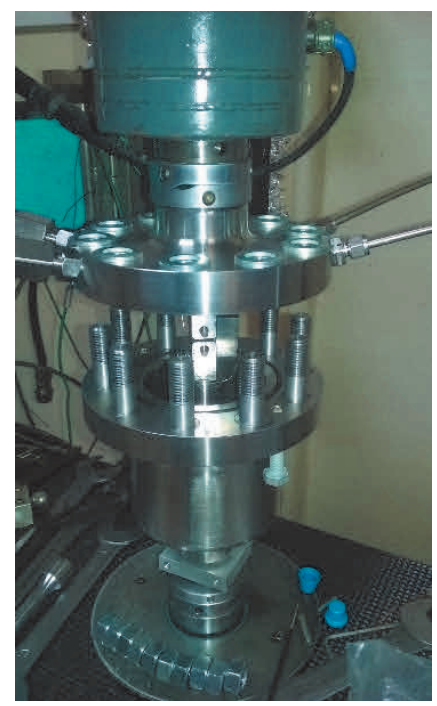

(a)

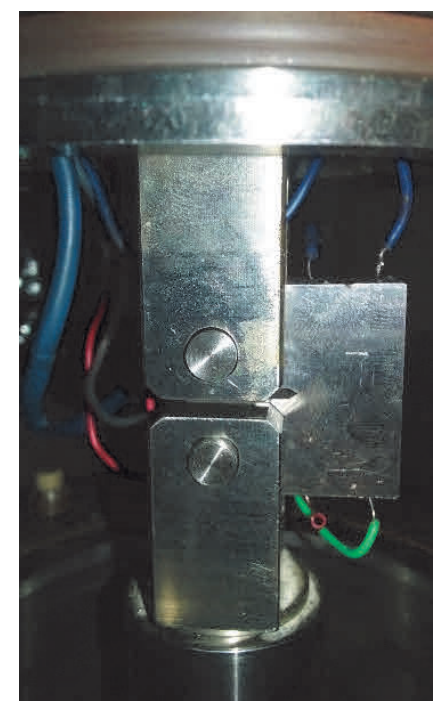

(b)

Figure 1(a) Hydrogen autoclave built in testing machine MTS $100 \mathrm{kN}$, (b) Detail of test specimen with welded electrodes for potential method

For the assessment of unfavorable effect of hydrogen on fatigue properties, namely fatigue crack growth rate, was used comparison of fatigue crack growth rate in the air and in high pressure hydrogen in the area of Paris law. Previous measurements [4] confirmed that potential method on $1 / 2 \mathrm{C}(\mathrm{T})$ specimens is applicable approximately up to the crack length $17 \mathrm{~mm}$ (70\% of specimen width). After reaching this length, values of potentials start to descend and further crack propagation is not measurable. Thus, choice of the loading has to respect this fact and have to be set so that stress intensity factor range interval covers significant part of Paris law interval.

\section{TEST RESULTS AND DISCUSSION}

As a tested material was used cylinder of low - alloyed 34CrMo4 steel. Both tests - in the air and in high pressure hydrogen - were performed at room temperature with frequency $8 \mathrm{~Hz}$ which was chosen due to possibilities of testing machine together with obtaining sufficient amount of dates from potential method system. Pre-cracking the specimens and subsequently fatigue crack growth rate measurement was performed at load ratio $\mathrm{R}=0.1$ according to ISO 12108 [5]. Stress amplitude was chosen so that would be covered interval of stress intensity factor range approximately $\Delta \mathrm{K}=10-30 \mathrm{MPa} \cdot \mathrm{m}^{1 / 2}$.

The relationship between fatigue crack growth rate and stress intensity factor was introduced by Paris [6]. Paris law is visualized on log-log plot and expressed by equation (1). 
$\frac{d a}{d N}=C \cdot \Delta K^{m}$

where:

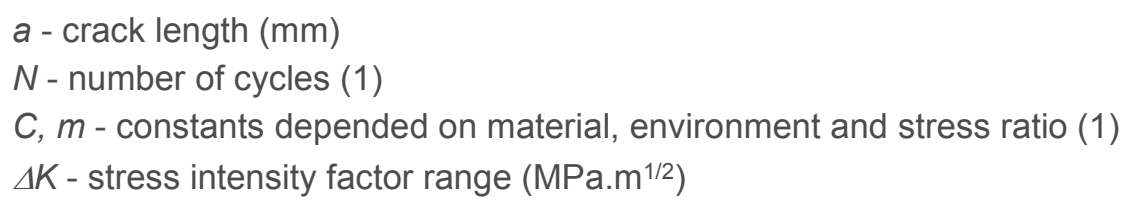

During the first test in the air was crack length measured by potential method and simultaneously by optical measurement. Crack length was also derived from previously assembled calibration curves. In Figure 2 is obvious that optically measured values are in good accordance with results obtained by potential method. On this place is necessary to emphasize that optical measurement is performed only on specimen surface and does not respect curvature of the crack so that small difference between both values is acceptable.

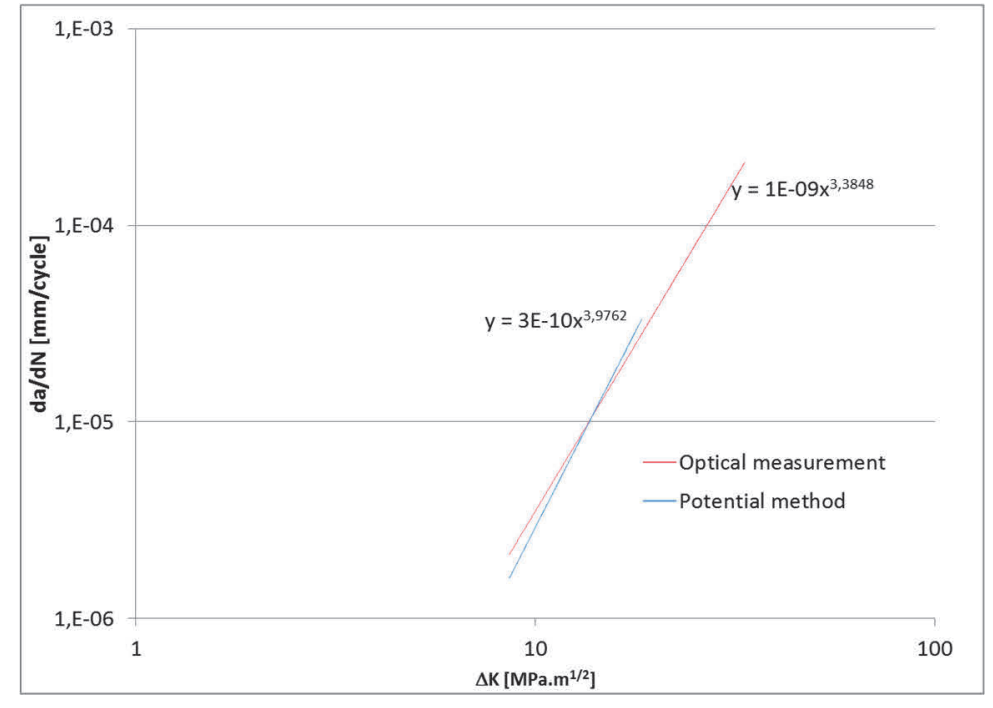

Figure 2 Comparison of fatigue crack growth rate between optical and potential method in the air

Second test was performed in hydrogen at pressure $15 \mathrm{MPa}$. This pressure is prescribed for testing of cylinders according to ISO 11114-4 [2]. Crack length was measured by potential method. Measurement was terminated at stress intensity factor range $\Delta \mathrm{K}=21.4 \mathrm{MPa} \cdot \mathrm{m}^{1 / 2}$ because maximal value of fatigue crack length for usability of potential method was achieved. Comparison of both curves is shown in Figure 3. In this Figure is conclusively confirmed negative effect of hydrogen on fatigue crack growth rate of $34 \mathrm{CrMo} 4$ steel. This effect is determined by higher value of both constants in Paris law equation. Especially exponent $m$ then expresses that effect of high pressure hydrogen significantly grows with increasing crack length.

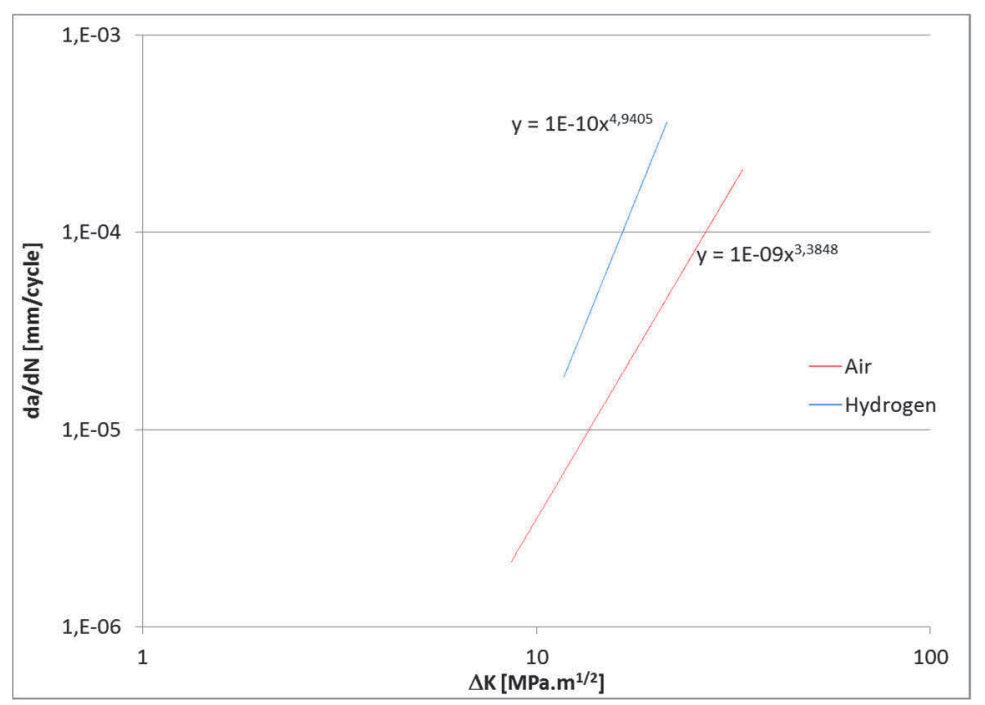

Figure 3 Comparison of fatigue crack growth rate in the air and in high pressure hydrogen 
After each test were specimens unloaded and broken in liquid nitrogen. Fracture surfaces of both specimens were subsequently subjected to analysis using scanning electron microscope. General view on both specimens taken by digital microscope KEYENCE is shown in Figures 4 (a) and 4 (b). In Figure 4 (b) are clearly visible areas of pre-cracking and dynamic loading in hydrogen.

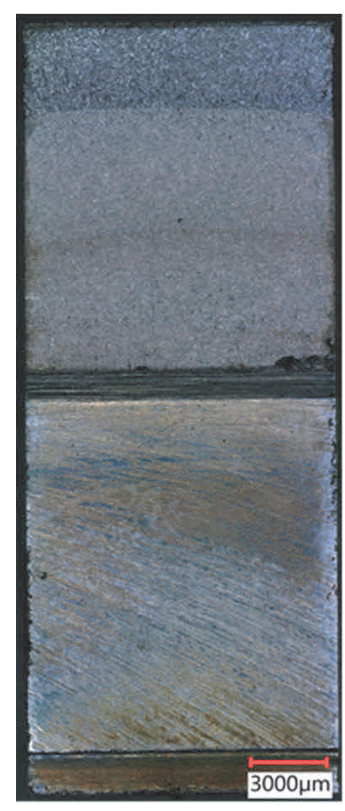

(a)

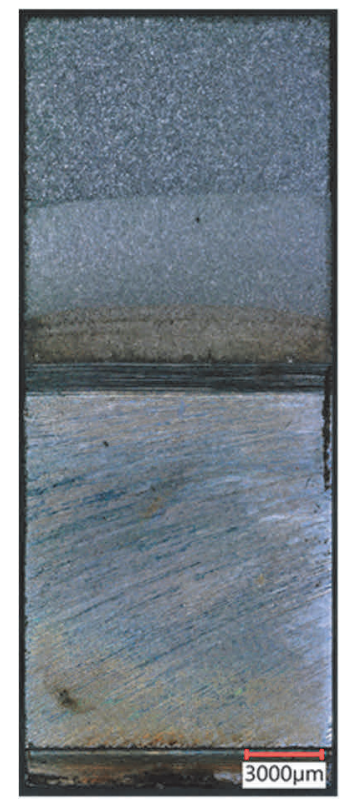

(b)

Figure 4 General view on broken 1/2C(T) specimens tested in (a) air, (b) hydrogen

Areas of initial crack did not show any differences. Because both specimens were precracked in the air and at the same load ratio, is this region characterized by transcrystalline cleavage fracture which is shown in Figure 5(a). However expected changes in morphology were observed in regions of fatigue crack growth. Whereas on the specimen tested in the air were observed, signs of fatigue damage characterized by striations (Figure 5(b)) and transcrystalline cleavage fracture, on fatigue crack growth surface, on the specimens tested in hydrogen was found a change in fracture mechanism (Figure 6(a)). Except transcrystalline cleavage fracture were observed also smooth intercrystalline blocks (Figure 6(b)).

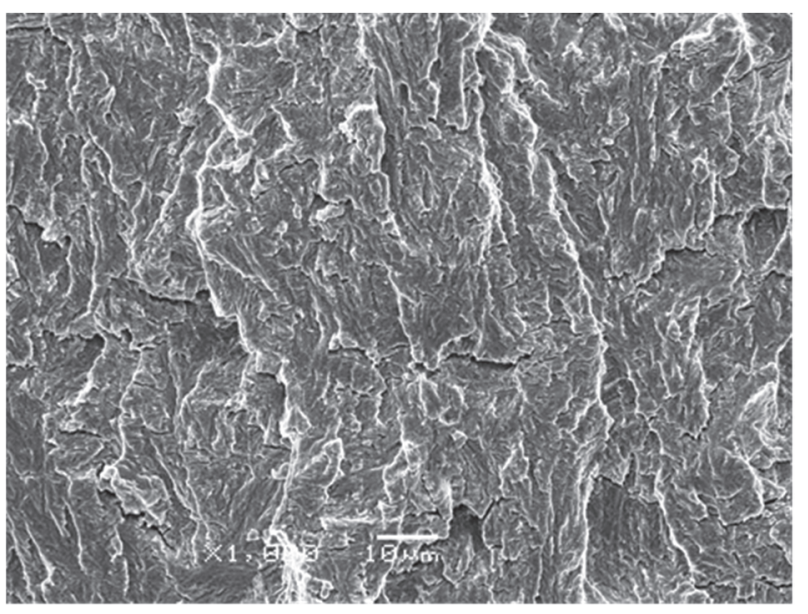

(a)

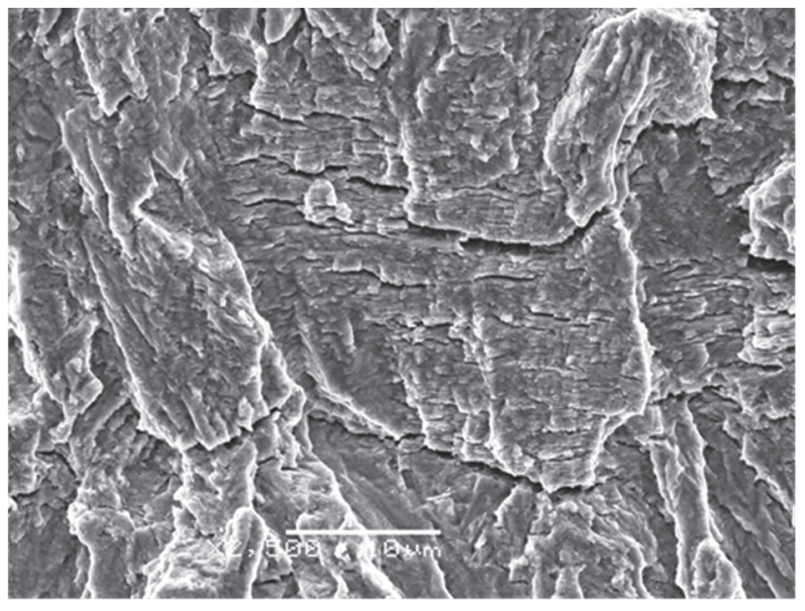

(b)

Figure 5 (a) Transcrystalline cleavage fracture, (b) striations on fracture surface of specimen tested in the air 
Test results obtained in this paper can be compared with work [7], where was also observed negative effect of hydrogen on fatigue crack growth rate of 34CrMo4 steel, which was more significant with increasing hydrogen pressure. Comparison between both results revealed better resistance of 34CrMo4 steel cylinder characterized by lower fatigue crack growth rate at the same stress intensity factor. The reason is probably higher metallurgical purity of steel used for cylinder production. However common sign for both results is the same fracture morphology after loading in hydrogen including combination of transcrystalline fracture and intercrystalline blocks.
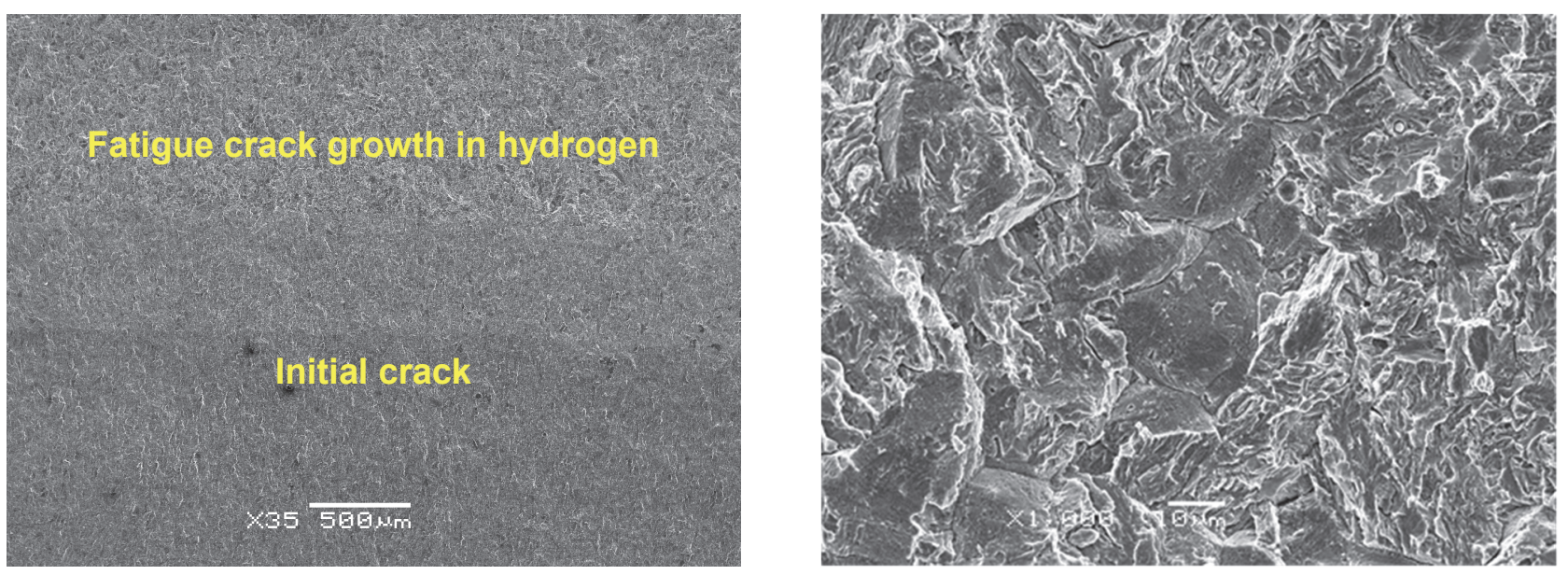

Figure 6(a) Change in fracture morphology between cycling in the air and hydrogen, (b) intercrystalline blocks on the specimen surface after loading in hydrogen

Effect of hydrogen can be also expressed using HEE index (Hydrogen environment embrittlement). This index usually expresses the degradation of certain mechanical properties that occur while the material is under mechanical loading and exposed to gaseous hydrogen environment as compared to air or an inert environment. Usually is HEE index calculated as a ratio of notched tensile strength of the hydrogen exposed specimen to specimen tested in air here we have calculated HEE for two different levels of stress intensity factor range see Table 1.

From the results summarized in the Table 1 can be clearly concluded that hydrogen effect increases with applied stress intensity factor range.

Table 1 HEE values for two levels of stress intensity factor

\begin{tabular}{|c|c|c|c|}
\hline$\Delta \mathrm{K}\left[\mathrm{MPam}^{0,5}\right]$ & da/dN Hydrogen $[\mathrm{mm} / \mathrm{cycle}]$ & da/dN Air [mm/cycle] & HEE \\
\hline 10 & $9.10^{-6}$ & $2.10^{-6}$ & 3.59 \\
\hline 20 & $3.10^{-4}$ & $9.10^{-5}$ & 10.56 \\
\hline
\end{tabular}

\section{CONCLUSIONS}

Experimental part of the paper was focused to determination of high pressure hydrogen effect on fatigue properties of $34 \mathrm{CrMo} 4$ steel used for cylinders production. All experiments were performed in hydrogen autoclave developed and produced in MATERIAL AND METALLURGICAL RESEARCH Ltd. For quantification of hydrogen effect was used fatigue crack growth method determined on 1/2C(T) specimens taken from received cylinder. Fatigue crack growth rate was measured by potential method.

Test results of fatigue crack growth rate of $34 \mathrm{CrMo} 4$ steel prove completely different fatigue behavior in the air and in pure hydrogen at pressure $15 \mathrm{MPa}$. Significant effect of hydrogen resulted in considerable increase of 
fatigue crack growth rate in comparison with fatigue behavior in the air. On fracture surface of the specimen loaded in hydrogen were observed changes in morphology, especially characterized by intercrystalline blocks appearance.

\section{ACKNOWLEDGEMENTS}

This paper was created in the Project No. TK01030163 "Research and development of material characteristics needed for evaluation of reliability and lifetime of steels used for hydrogen industry" funded by the Technology Agency of The Czech Republic (TACR)

\section{REFERENCES}

[1] ISO 9809-1:2010, Gas cylinders - Refillable seamless steel gas cylinders - Design, construction and testing - Part 1: Quenched and tempered steel cylinders with tensile strength less than $1100 \mathrm{MPa}, 2010$.

[2] ISO 11114-4:2005 Transportable gas cylinders - Compatibility of cylinder and valve materials with gas contents Part 4: The test methods for selecting metallic material resistant to hydrogen embrittlement, 2005.

[3] KOREC, L. Odečitací jednotka pro měření potenciálovou metodou Techlab SRT-4K. Praha: Techlab. 2007.

[4] KANDER, L, ČÍŽEK P. and STEJSKALOVÁ Š.: Effect of high pressure hydrogen environment on fatigue crack growth rate properties of structural steels used for cylinders, In METAL 2017: 26 ${ }^{\text {th }}$ International Conference on Metallurgy and Materials. Ostrava: TANGER Ltd., Ostrava, 2017, pp. 826-831.

[5] ISO 12108:2012, Metallic materials - Fatigue testing - Fatigue crack growth rate method, 2012.

[6] PUGNO, N., CIAVARELLA, M., CORNETTI, P., and CARPINTERI, A. A generalized Paris' law for fatigue crack growth. Journal of the Mechanics and Physics of Solids. 2006. vol. 54, pp-1333-1349.

[7] PRIEST, A. H. Fatigue crack growth and fracture resistance of steels in high-pressure hydrogen environment. Report EUR 8191. Luxemburg: 1983. 